Revista Aspas

ppgac - USP

Especial

\title{
LUGAR DA CHUVA: CORPOS VIAJANTES EM URBANIDADES AMAZÔNICAS
}

\section{LUGAR DA CHUVA: TRAVELING BODIES IN AMAZONIAN URBANITIES}

\section{LUGAR DA CHUVA: CUERPOS DE VIAJEROS EN URBANIDADES} AMAZÓNICAS

\section{José Raphael Brito dos Santos e Wellington Douglas dos Santos Dias}

José Raphael Brito dos Santos

Mestre pelo Programa de Pós-Graduação em Artes Cênicas pela Universidade Federal de Uberlândia. Ator do Frêmito Teatro (AP) e do Núcleo de Pesquisas Teatrais Rascunho (MA). Professor do curso de Teatro da Universidade Federal do Amapá, subárea Interpretação.

Wellington Douglas dos Santos Dias Mestre em Direção Teatral pela RITCS School of Arts - Erasmus Hoggeschool University of Brussels. Ator do Frêmito Teatro (AP) e idealizador do projeto TECNO BARCA. Professor do curso de Teatro da Universidade do Estado do Amazonas, subárea Direção e Ensino do Teatro. 


\section{Resumo}

O artigo visa apresentar as experiências de corpo em diálogo com espaços e urbanidades amazônicas do processo de criação do espetáculo Lugar da Chuva, dos grupos Frêmito Teatro (AP) e Agrupamento Cynétiko (SP), que ocorreu nas cidades de Macapá e Santana, no estado do Amapá. O panorama teórico desta pesquisa conversou com as seguintes questões e seus respectivos autores: "estados de presença" com Eleonora Fabião (2010), "a rua e cidade enquanto trama" com André Carreira (2009) e a "dimensão ancestral da floresta e seus povos" com Davi Kopenawa (2015), dentre outros. Esta reflexão também objetiva ampliar as perspectivas sobre a sensibilização do corpo do ator, a busca por investigações nas urbanidades amazônicas e também transitar entre noções de corpo e espaço. Neste sentido, apresentaremos parte da trajetória desta experiência, articulando reflexões sensíveis e poéticas sobre o processo.

Palavras-chave: Lugar da Chuva, Corpos amazônicos, Urbanidades.

\section{Abstract}

The paper presents corporal experiences in dialogue with amazonian spaces and urban areas in the process of creating the play Lugar da Chuva of the groups Frêmito Teatro (AP) and Agrupamento Cynétiko (SP) that happened in the cities of Macapá and Santana, in Amapá state. The theoretical panorama of the research deals with the following topics and authors: "states of presence" from Eleonora Fabião (2010), "the street and the city as a plot" from André Carreira (2009), "ancestral dimension of the forest and its people" from Davi Kopenawa (2015), among others. This reflection aims to broaden the perspectives on the awareness of the actor's body, the search for investigations in amazonian urban areas and moving between notions of body and space. In this sense, we will present part of the trajectory of this experience, articulating sensitive and poetic reflections.

Keywords: Lugar da Chuva, Amazonian bodies, Urbanities.

\section{Resumen}

El artículo presenta experiencias de diálogo del cuerpo con espacios y urbanidades amazónicas del proceso de creación del espectáculo Lugar da Chuva de los grupos Frêmito Teatro (AP) y Agrupamento Cynétiko (SP) que tuvo lugar en las ciudades de Macapá y Santana, en el estado de 
Amapá. El panorama teórico de esta investigación articuló las siguientes cuestiones y sus respectivos autores: "estados de presencia" con Eleonora Fabião (2010), "la calle y la ciudad como trama" con André Carreira (2009), "dimensión ancestral de la floresta y sus pueblos" con Davi Kopenawa (2015), entre otros. Esta reflexión también tiene como objetivo ampliar las perspectivas acerca de la sensibilización del cuerpo del actor, la búsqueda por investigaciones en las urbanidades amazónicas, así como transitar entre nociones de cuerpo y espacio. En este sentido, presentaremos parte de la trayectoria de esta experiencia, articulando reflexiones sensibles y poéticas acerca del proceso.

Palabras clave: Lugar da Chuva, Cuerpos amazónicos, Urbanidades.

\section{Porto de Partida}

Neste artigo, refletiremos sobre o processo de criação do espetáculo Lugar da Chuva, dos grupos Frêmito Teatro (AP) e Agrupamento Cynétiko (SP), que ocorreu com experiências e vivências em diferentes espaços das cidades de Macapá e Santana, no estado do Amapá. Desta forma, apresentaremos a seguir reflexões acerca dos corpos dos atores na relação de confronto e provocações com urbanidades amazônicas selecionadas para a pesquisa da montagem deste espetáculo.

A equipe do espetáculo foi composta pelo diretor e idealizador do projeto Otávio Oscar, pela dramaturga Ave Terrena, pela vídeo-artista Luciana Ramin, pela diretora de arte Daniele Desierrê e pelos atores Raphael Brito e Wellington Dias.

Cabe ressaltar que as experiências nestes espaços ocorreram com investigações relacionais de corpo e cidade. Entendendo o corpo como um organismo vivo e poroso, repleto de questões políticas, históricas e sinestésicas em atravessamento com a cidade amazônica que mescla diferentes espacialidades e territórios híbridos de urbanidade, rios e florestas.

Os espaços onde ocorreram as experimentações práticas foram: Parque do Forte, Fortaleza de São José e rampa do Santa Inês, na zona central de Macapá; Abacate da Pedreira, comunidade quilombola às margens 
do rio Pedreira, zona rural da capital; madeireiras do bairro das Pedrinhas e palafitas do bairro Araxá, na zona sul de Macapá; e Ilha de Santana, no rio Amazonas, localizada no município de Santana, cerca de $20 \mathrm{~km}$ da capital. Para este artigo, selecionamos as pesquisas realizadas em três espaços: Fortaleza de São José, palafitas do bairro do Araxá e Ilha de Santana.

\section{Blocos de corpos, pedras, sangue e suor}

O primeiro espaço/corpo foi a Fortaleza de São José, localizada no centro da cidade de Macapá, às margens do Rio Amazonas, construída em decorrência de possíveis conflitos entre europeus e, atualmente, é um ponto turístico para visitações. Reconhecida como patrimônio histórico nacional desde 1950.

Erguida no século XVIII, foi chefiada pelos portugueses e construída com mão de obra negra e indígena, mas sem qualquer menção presente nos registros históricos ao trabalho braçal desses corpos, o que demonstra o apagamento e invisibilização dessas populações na Amazônia.

Figura 1 - Laboratório experimental na Fortaleza de São José, Macapá-AP

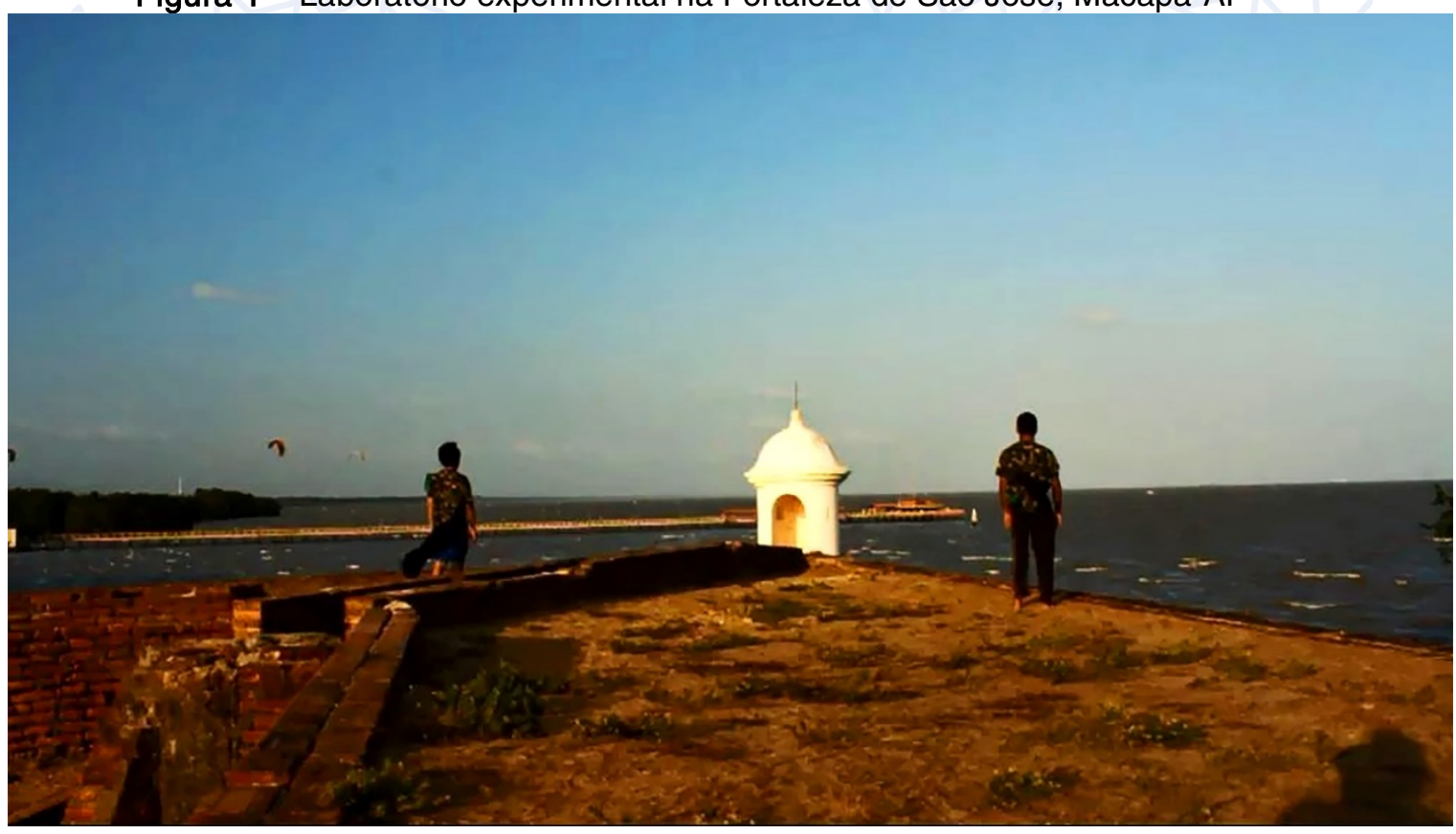

Fonte: Registro de Luciana Ramin 
Em nossa prática laboratorial dentro da Fortaleza, iniciamos no alto dos baluartes, nos posicionamos contra o vento que vinha do Rio Amazonas, que consequentemente colocava nossos corpos em estado de alerta com tensionamentos musculares involuntários, principalmente, das pernas e do tronco para manter o corpo ereto e fixado ao chão, os quais variavam conforme a intensidade e direção da ventania.

Corpo e percepção aguçadas na tentativa de experienciar a presença de micropartículas sensíveis da pele: "quanto mais atenta estou, mais inapreensível se torna o instante. Imersa num momento infinito. Percepção é participação. Sou parte; logo, existo. Ou ainda: participar; logo, existir" (FABIÃO, 2010, p. 325).

Entre o silêncio e o som das rajadas de ar, fixamos a visão para a infinitude, em um exercício de espera rememorando a chegada de possíveis navios com inimigos prestes a atacar; sensação de incerteza, ansiedade e paralisia com corpos estaticamente em movimento, tal como a singularidade de uma "imobilidade impossível" na reflexão apontada por Eleonora Fabião (2010) na citação a seguir.

Fico de pé e imóvel - apenas esforço e tensão necessários para manter-me de pé e imóvel. Já sorrio; não há imobilidade possível. Parada, me movo em direção à imobilidade. De pé, dançada pela dança mínima, pela nervura desta ação. [...] O contato dos pés com o chão, a zona de contato, superfície de interseção, ali, onde é pé e chão, onde o pé é chão e o chão, pé. (FABIÃO, 2010, p. 325).

O corpo agindo sob o espaço e o espaço agindo sob o corpo em um diálogo rizomático que transgride territórios sensíveis e produz acontecimentos instáveis, e, dessa forma, o espaço possibilita experiências impalpáveis, inconclusas e carregadas de histórias e vestígios memoriáveis (HISSA; NOGUEIRA, 2013).

Em seguida experimentamos relações corporais em grandes rampas inclinadas. Em plano baixo, rastejamos compulsoriamente na ânsia pela chegada ao topo, com movimentos fortes em direção ascendente e em contrapartida à uma força contrária que nos puxava para trás. Desta forma, empregamos energia em grande proporção exaustivamente. 
Essa parte do laboratório também fez alusão aos ancestrais que construíram a Fortaleza e as situações de opressão, revolta, resistência, indignação e tortura dos quais foram submetidos, nesse espaço que carrega marcas simbólicas e energéticas que eram impossíveis de serem descartadas na prática laboratorial.

Em seguida, entramos também na capela de São José; sentamos nos bancos e contemplamos o altar em uma ação física que remete ao comportamento social comumente assumido por cristãos no interior de espaços sagrados. Ajoelhamos e rezamos, nos permitindo sentir as energias centenárias e simbólicas do espaço. A atmosfera de religiosidade nos trouxe um certo comedimento das ações, anulação de movimentos bruscos e silenciamento de vozes. Caminhamos no interior da pequena capela e nos debruçamos nas janelas para olhar o exterior por um bom tempo; o silêncio e o vazio nos remetiam aos primeiros corpos que frequentaram a Fortaleza.

Para os autores Cássio Hissa e Maria Luísa Nogueira (2013), "o espaço também é produtor de subjetividade, e, por isso, está sempre carregado de memórias. Desse modo, o corpo revela-se muito mais que seu mínimo instrumento para agir e limite à ação". (HISSA; NOGUEIRA, 2013, p.61). Portanto, constatamos que no interior destes espaços é latente a construção de um imaginário regido por normas de condutas da sociedade cristã com uma série de regras e hábitos que nos conduzia incoscientemente à uma adequação corporal normatizada pelas imposições religiosas.

Nesse sentido, a energia do espaço atravessou nossos corpos intercambiando relações corporais e produzindo provocações sobre a Fortaleza de São José, além de estimular o surgimento de corporeidades docilizadas, tensas, sutilmente agressivas e inquietas; colocando em cheque a figura dos fundadores portugueses que empreenderam na região modos violentos de relacionamento humano para com os corpos indígenas e negros escravizados, estilhaçados e suplantados por entre os escombros nessa sanguinária colonização europeia. 


\title{
Flutuações às margens do rio Amazonas
}

O segundo espaço/corpo selecionado para refletirmos sobre nosso processo criativo é o bairro do Araxá, localizado às margens do rio amazonas em Macapá. Ali, sem terreno próprio para residir, parte dos moradores ocupam a beira do rio com suas casas e pontes de madeira. Observamos e caminhamos por essas pontes a fim de desenvolver experimentações corporais em relação à essa arquitetura e paisagem urbana expressiva das condições sociais das periferias amazônicas. Nesse sentido, vale refletir sobre a visão de André Carreira sobre a rua e a cidade:

\begin{abstract}
A rua é um tramado, um espaço de justaposição de usos e o teatro, em sua operação poética, passa a fazer parte dessa trama, por isso é impossível supor que a cidade possa funcionar apenas como cenografia, pois a presença do acontecimento teatral também será redefinida pelos usos sociais e culturais predominantes, e aquilo que poderia ficar atrás da cena como elemento cenográfico sempre ocupará interstícios da dramaturgia porque é um dispositivo vivo por onde circulam pessoas em seu cotidiano (CARREIRA, 2009, p. 4).
\end{abstract}

Em se tratando da cidade como dispositivo vivo e dinâmico em seus fluxos humanos, paisagens e espaços, podemos acrescentar que a experiência no Araxá nos evidenciou percepções das urbes enquanto trama, onde aspectos sociais, históricos e naturais complexificam as ações e as existências dos corpos que habitam e transitam nelas, seja na vida cotidiana ou em experiências poéticas.

Após um tempo de caminhada livre, definimos trajetos nas pontes e os repetimos com variações de ritmos, percebendo sutilmente em nós as sensações corporais de desequilíbrio ao caminhar por essas estruturas de madeira que se movem com as marés ${ }^{1}$ do rio Amazonas.

Em alguns trechos, as pontes pareciam firmes, como se estivessem de fato fincadas em terreno sólido, mas em outros pontos, sentíamos a iminência de seu desmonte pela força das águas e do vento constante na beira do rio.

\footnotetext{
${ }^{1}$ Por conta do volume de água e da influência do oceano o rio Amazonas apresenta o fenômeno de maré.
} 
Dessa forma, nossos corpos se mantinham em variações de equilíbrio e desequilíbrio. Pisar nas madeiras e ouvir o estalar delas nos colocava em estado de alerta, onde nossos músculos involuntariamente se tensionavam na tentativa de manter-se em equilíbrio mesmo no deslocamento de nossos eixos corporais.

Figura 2 - Laboratório experimental no Bairro do Araxá, Macapá-AP

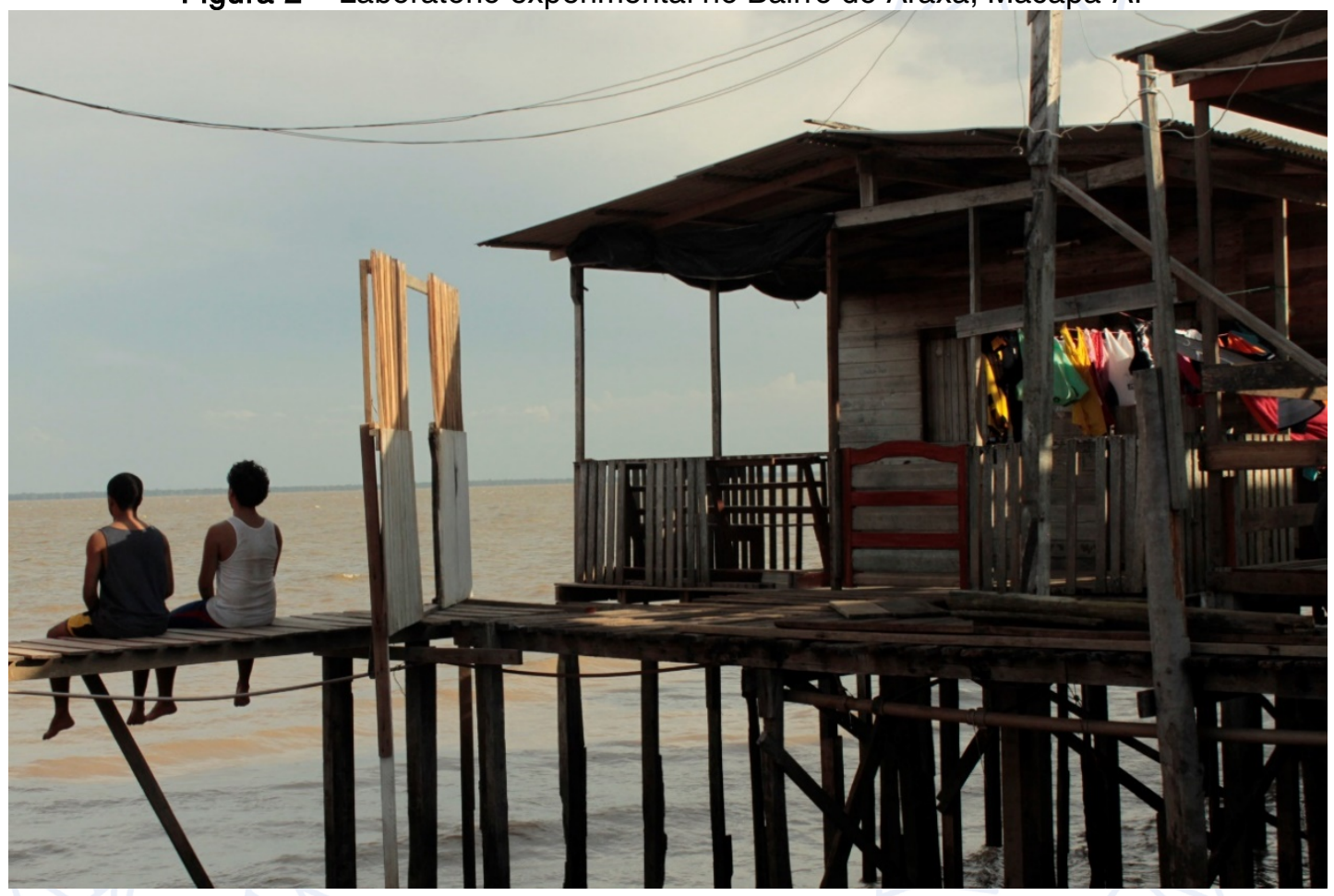

Fonte: Registro de Luciana Ramin

Além de caminhadas, vivemos momentos de contemplação estática no lugar. A brisa incessante fazia nossos corpos relaxarem ao som das ondas do rio abaixo de nós. Ao final de uma ponte ficamos sentados criando ações físicas e imagens espontâneas; entramos em estado de suspensão, perdendo noção de tempo, respirando suave e sentindo a ventania das marés.

Decidimos entrar no rio caminhando com a água até nossos joelhos. $A$ argila mole desafiava nossa ação corporal, exigindo esforço das pernas e pés; tropeçamos, caímos, gargalhamos e seguramos a mão um do outro para resistir à força das ondas do rio. Para Rengel et alii (2015), em referência à pesquisa de Laban sobre ação corporal: 
Ação e/ou ação corporal é uma sequência de movimentos onde uma atitude do agente resulta num esforço definido, o qual, por sua vez, imprime uma qualidade ao movimento. [...] Laban ressalta que atitude, esforço e movimento dão-se simultaneamente e que o termo corporal engloba os aspectos intelectuais, espirituais, emocionais e físicos, ou seja, o corpo é uma totalidade complexa. Há infinitas ações: correr, torcer, pular, engatinhar, saltitar, enfim todas as ações que os agentes fazem, sempre com a ideia de Laban de que a ação não é só física ou mecânica (RENGEL et alii, 2015, p. 1).

Partindo dessa ideia, vê-se ação corporal enquanto amálgama de camadas físicas e subjetivas do indivíduo, acionadas a partir da atitude do corpo que se movimenta no espaço reverberando qualidades e sensações em si e no seu entorno, a exemplo de uma rede, onde cada ponto vibra conjuntamente à medida que toca ou é tocado por algum estímulo ou superfície.

Com metade de nossos corpos submersos na água do rio, sentimos a pressão do vento e o calor tropical - típico dessa região cortada pela Linha do Equador - aumentando pela nossa exposição ao sol. Em seguida, percebemos a rapidez do rio enchendo ao nosso redor, sinalizando que era hora de voltarmos à terra firme.

Dessa experiência de flutuação de nossos corpos tanto nas caminhadas pelas pontes quanto nas águas do rio Amazonas, transportamos para a pesquisa do espetáculo qualidades corporais e movimentos sinuosos que remetessem às sensações corpóreas vividas no Araxá.

\section{A presença do invisível}

O terceiro espaço/corpo no processo de criação ocorreu na llha de Santana, localizada no município de Santana-AP, atravessamos em um pequeno barco que faz o trajeto do porto para as ilhas desse município, conhecido pelas árvores samaúmas (ou sumaúmas) de 80 metros de altura.

No barco, o som do motor nos impulsionou à uma hipnose multifacetada de sentidos em relação ao vento, o som das águas e o verde da floresta, em um constante navegar de si. 
Ao chegarmos em uma das praias do rio Amazonas, experimentamos relações corporais com tecidos, movimentos e ações em fluxo que nos levaram a criar imagens, caminhadas, corridas, saltos, atritos entre nós, a água e a argila do chão da praia.

Entramos na floresta e sentimos a diferença de temperatura em relação à praia. Após um tempo de caminhada encontramos uma árvore samaúma que nos provocou um estado de corpo em suspensão. A força da floresta, o cheiro ancestral, o silêncio e o som dos bichos nos transportou a uma perda sutil de noção de tempo cronológico e fomos capturados pela magia deste corpo-floresta.

Esta experiência nos fez perceber a samaúma como coração da ilha, gigante, pulsante, poderoso, vívido e transcendente. Segundo o xamã yanomami Davi Kopenawa, "a floresta respira, mas os brancos não percebem. Não acham que ela esteja viva. No entanto, basta olhar para suas árvores, com as folhas sempre brilhantes. Se ela não respirasse, estariam secas". (KOPENAWA; ALBERT, 2015, p. 472).

Dessa forma, em nosso processo criativo, percebemos a floresta enquanto corpo e organismo vivo que transcende a ideia de uma paisagem estática e carrega uma série de crenças e interligações dos corpos que habitam nela, seja animais, vegetais ou humanos.

Com seus cipós altos e firmes, brincamos de nos balançar e deslocar de um ponto a outro no caule da samaúma. Ali, mesmo inconscientemente, empregamos habilidades corporais como força, equilíbrio e precisão de movimentos na relação com a árvore. A tentativa de uma relação dialógica com a floresta nos exigiu - minimamente - ter consciência de sua grandeza nua, crua e avassaladora, sem influência humana. Por essa razão, despimos nossos corpos almejando um estado natural de vida, tal como a floresta. 
Figura 3 - Laboratório experimental na llha de Santana, localizada no município de Santana-AP

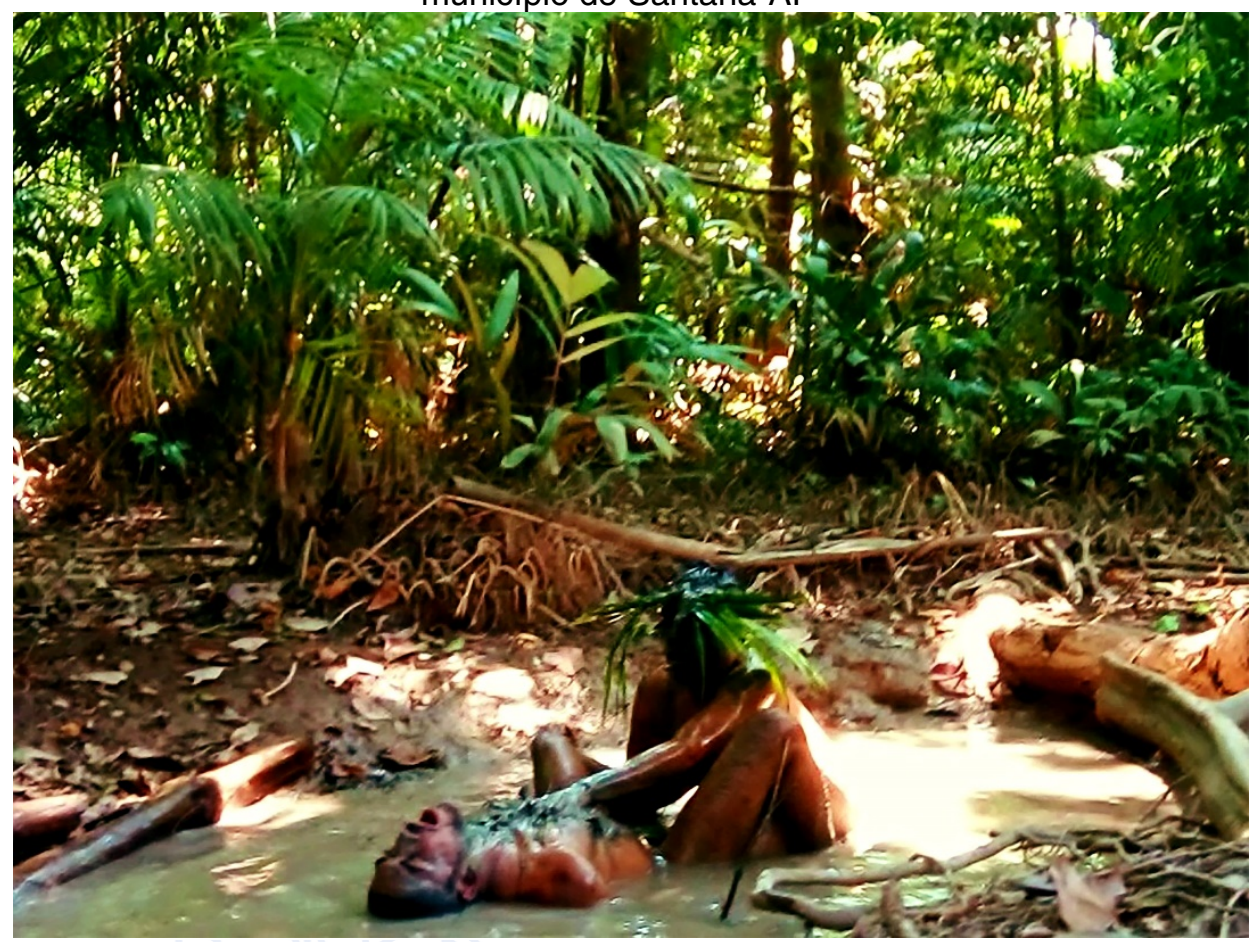

Fonte: Registro de Luciana Ramin

Caminhamos nus na mata até chegarmos em um lago que se formou com a água das chuvas. Entramos nele, nos misturamos com lama e travamos um contato corporal utilizando materiais como folhas, galhos de árvores, argila, água, entre outros. Produzimos grunhidos, sons nasalados e sonoridades pelo atrito de nossos corpos com o espaço. Entramos em conexão íntima, recíproca e ritualística nos despindo de qualquer condução nessa relação corporal, imersos em sensorialidades afloradas no deslizar da lama e da água nessa espécie de ritual em que um corpo abre caminho para outro, desautomatizando ações previamente elaboradas, tal como reflete Fabião (2010):

Estamos mais habituados a agir do que a distensionar, a ponto de
sermos agidos; somos treinados para criar e executar movimento,
não para ressoar impulso; geralmente sabemos ordenar e dar
ordens ao corpo mais e melhor do que sabemos nos abrir e escutar.
A busca por um corpo conectivo, atento e presente é justamente a
busca por um corpo receptivo. A receptividade é essencial para que
o ator possa incorporar factualmente e não apenas intelectualmente
a presença do outro. (FABIÃO, 2010, p. 323)


Nessa experiência ativamos elementos ancestrais que nos remeteram à nossa insignificância diante desse organismo, em que nosso repertório de técnicas corporais não se sobrepôs à magnitude e complexidade da presença e fluxos energéticos da floresta. Nesse sentido, Kopenawa \& Albert (2015) nos elucida o seguinte:

\footnotetext{
Não pensem que a floresta é vazia. Embora os brancos não os vejam, vivem nela multidões de espírito, tantos quantos animais de caça. Por isso suas casas são tão grandes. Tampouco pensem que as montanhas estão postas nas florestas, à toa sem nenhuma razão. São casas de espíritos. Casas de ancestrais. (KOPENAWA; ALBERT, 2015, p. 118)
}

Nessa dimensão de mistério e tentativa de compreensão racional das camadas físicas e subjetivas da floresta, pudemos experienciar em nossas corporeidades diversos atravessamentos que deslocaram sutilmente nossas percepções e sinestesias em relação ao corpo-floresta repleto de presenças invisíveis, porém possíveis de serem sentidas.

\section{Atracação temporária}

Na pesquisa do espetáculo Lugar da Chuva, vivenciamos experiências sensoriais e de atravessamento de corpos e espacialidades urbanas e naturais nas cidades de Macapá e Santana (AP). No artigo, buscamos refletir sensações corpóreas, subjetivas, aspectos históricos, políticos e cotidianos da vida de corpos que habitam a Amazônia.

Assim, trazemos perspectivas de corpos amazônicos afetados pela memória, urbanidade e ecossistemas da região, transitando por territórios de pesquisa corporal que nos proporcionou relacionamentos com complexidades de uma Amazônia ancestral e atual.

A relação de corpo e cidade neste artigo atravessa transversalidades e compreende o corpo não somente enquanto fator orgânico, mas também inorgânico. Neste último caso, reconhece o espaço como dispositivo corporal que carrega em sua estrutura camadas de histórias e memórias capazes de afetar condicionamentos relacionais. 
Dessa forma, também compreende o corpo enquanto noção de espaço, colocando-o não somente como um ser humano que transita por territórios, mas que também é território, faz parte do todo como um órgão que atravessa toda a estrutura.

Corpo-Cidade. Cidade-Corpo. Espaço. Território. Estrutura. Urbanidades. Essas são algumas ideias que fazem parte deste trabalho. Porém, faz-se necessário discorrer que o corpo-cidade deste artigo transcorreram por pensamentos decoloniais com corpos de atores da Amazônia Legal: Raphael Brito (nordestino, maranhense, que reside em Macapá) e Wellington Dias (nortista, amapaense, que reside em Manaus) e cidades-espaço de pesquisa que fazem parte do Estado do Amapá (Macapá e Santana).

Percorremos pistas que nos levaram a questões de conjuntura espacial e histórica, além da invisibilização da memória e a violência contra populações ancestrais indígenas e negras escravizadas na construção de obras nas cidades de Macapá e Santana, como a Fortaleza de São José, símbolo bélico da colonização europeia violenta na região.

O processo civilizatório da humanidade apresentou, em diversos aspectos, a ideia de que a urbanidade estava associada à construção de cidades totalmente verticais e cheias de prédios, com estruturas modeladas e controladas pelo homem. A urbanidade no Amapá possui forte preponderância de camadas amazônicas e além disso mistura cidade e floresta, cortadas pela Linha do Equador com altas temperaturas e um elevado volume de chuvas durante o ano.

Nessa viagem chegamos ao bairro do Araxá com suas palafitas (casas de madeira suspensas às margens do rio Amazonas) e pontes de madeira, onde nossas corporeidades tiveram seus eixos de equilíbrio deslocados e mergulhadas em afetações, sensorialidades e percepções dilatadas através de caminhadas, repousos e desafios naquele espaço carregado de contrastes entre o urbano e o natural, bastante comum nas periferias das cidades amazônicas.

As cidades desta pesquisa apresentam peculiaridades que não estão rotuladas em condições extremamente cimentadas em formatos cartesianos, comumente presente na maior parte das cidades brasileiras, pois no norte do 
País as urbanidades apresentam uma organização geográfica rizomática, entrecortada e ramificada, onde as florestas e os rios são elementos determinantes da organização espacial e fluxos dos corpos que habitam a região.

Por fim, chegamos na llha de Santana, no encontro com sua praia no rio amazonas e a floresta com árvores de samaúma gigantes. Ali, nossas presenças corporais cederam lugar para a imensidão energética, sutil, vibrante e monumental deste organismo complexo e vivo do espaço amazônico. No desnudamento de nossos corpos, buscamos caminhos de sensibilização e estados de presença menos programados e mais receptivos uns para os outros, no acolhimento de nossas vulnerabilidades físicas, espirituais e sensitivas que esse espaço amazônico nos convidou a experienciar.

Em diálogo com esse espaço, os corpos dos atores não se condicionaram necessariamente na execução de técnicas e laboratórios teatrais conhecidos no âmbito da prática atoral, a exemplo de trabalho de construção psicológica de personagens. Já em nosso processo criativo, fomos estimulados a criar a partir da relação de nossos corpos em diálogo com os espaços vivenciados, o que proporcionou o surgimento de uma experiência cênica navegante por ilhas e camadas do percurso de dois viajantes em constante mergulho e tomadas de consciência a partir do espaço amazônico.

\section{REFERÊNCIAS BIBLIOGRÁFICAS}

CARREIRA, André. Ambiente, fluxo e dramaturgias da cidade: materiais do Teatro de Invasão. O Percevejo Online, vol. 01, fasc. 01, jan./jun. 2009. Disponível em: $<$ http://www.seer.unirio.br/index.php/opercevejoonline/article/view/482>. Acesso em 01 jun. 2020.

FABIÃO, Eleonora. Corpo Cênico. Estado Cênico. Revista Contrapontos, vol. 10, n. 3, p. 321-326, set./dez. 2010. Disponível em:

$<$ https://siaiap32.univali.br/seer/index.php/rc/article/view/2256>. Acesso em 03 jun. 2020. 
HISSA, C. E. V.; NOGUEIRA, M. L. M. Cidade-Corpo. Revista da UFMG, Belo Horizonte, vol. 20, n.1, p.54-77, jan./jun. 2013, Disponível em:

$<$ https://www.ufmg.br/revistaufmg/downloads/20/3-cidade-

corpo cassio hissa e maria nogueira.pdf>. Acesso em 05 jun. 2020.

KOPENAWA, Davi; ALBERT, B. A Queda do Céu: palavras de um xamã yanomami. São Paulo: Companhia das Letras, 2015.

RENGEL, Lenira Peral et alii. Elementos do Movimento na Dança. Salvador: UFBA, 2017. 102 p. Disponível em:

$<$ http://www.danca.ufba.br/arquivos pdf/Livros/e-book EMD.pdf>. Acesso em 01 jun. 2020. 